С.А. АРТЮШКИН ${ }^{1}$, Д.М.Н., профессор, С.В. РЯЗАНЦЕВ ${ }^{2}$, Д.М.Н., профессор, Н.В. ЕРЕМИНА ${ }^{1}$, Д.М.Н., профессор, С.А. ЕРЕМИН ${ }^{2}$, к.М.Н.

${ }^{1}$ Северо-Западный государственный медицинский университет Минздрава России, Санкт-Петербург

${ }^{2}$ Санкт-Петербургский научно-исследовательский институт уха, горла, носа и речи Минздрава России

\title{
СОВРЕМЕННЫЕ ФИТОСЕКРЕТОЛИТИКИ
} В ЛЕЧЕНИИ ОСТРОГО РИНОСИНУСИТА

\begin{abstract}
Острый ринит (по МКБ-Х, острый назофарингит, насморк - Ј00) и острый синусит (Ј01) составляют значительную долю в структуре острых заболеваний верхних дыхательных путей (J00-Ј06). Назначение антибактериальных препаратов при вирусных поражениях ЛОР-органов и недоказанной или неподтвержденной бактериальной природе заболевания считается ошибочным и опасным. В связи с этим при лечении ОРС повышается роль патогенетически обоснованной терапии. Особое внимание в выборе лекарственных средств при ОРС уделяется использованию фитопрепаратов комплексного действия, что нашло отражение в нормативных документах - группа фитопрепаратов (herbal medicine) введена в перечень средств по лечению ОРС у взрослых в документе EPOS-2012, в стандарты оказания медицинской помощи МЗ РФ и методические рекомендации, одобренные НМАО (Национальная медицинская ассоциация оториноларингологов).
\end{abstract}

Ключевые слова: острый риносинусит, фитопрепараты, миртол, ГелоМиртол ${ }^{\circledR}$.

S.A. ARTYUSHKIN ${ }^{1}$, MD, Prof., S.V. RYAZANTSEV², MD, Prof., N.V. EREMINA ${ }^{1}$, MD, Prof., S.A. EREMIN ${ }^{2}$, PhD in medicine

${ }_{1}^{1}$ North-Western State Medical University of the Ministry of Health of Russia, St. Petersburg

2 Saint-Petersburg Research Institute of Ear, Throat, Nose and Speech of the Ministry of Health of Russia

MODERN HERBAL MEDICINES IN THE TREATMENT OF ACUTE RHINOSINUSITIS

Acute rhinitis (ICD-X, acute nasopharyngitis, runny nose - J00) and acute sinusitis (J01) make up a larger proportion of all acute upper respiratory tract diseases (J00-J06). The prescription of antibacterial drugs for the treatment of virus diseases in the ENT area and the unproven or unconfirmed bacterial disease is considered erroneous and dangerous. In this regard, the role of pathogenetically justified therapy in the treatment of ARS increases. When choosing the medicines for ARS, particular attention is given to the use of herbal medicines with combination effect, which found its way into legislation - a group of herbal medicines is included in the list of ARS treatment medicines in adults in the EPOS-2012 document, and methodological recommendations approved by the National Medical Association of Otorhinolaryngologists.

Keywords: acute rhinosinusitis, herbal medicines, myrtol, GeloMyrtol ${ }^{\circledR}$.

стрый ринит (по МКБ-Х, острый назофарингит, насморк - Ј00) и острый синусит (Ј01) составляют значительную долю в структуре острых заболеваний верхних дыхательных путей (J00-Ј06). Острый ринит характеризуется развитием острого воспаления слизистой оболочки полости носа, острый синусит - острым воспалением слизистой оболочки околоносовых пазух. Они часто развиваются одновременно, что послужило основанием для появления термина «острый риносинусит». С помощью компьютерной томографии, являющейся «золотым стандартом» диагностики синусита, у 95\% больных ОРВИ при наличии ринологической симптоматики было выявлено разной степени выраженности поражение слизистой оболочки околоносовых пазух [1, 2].

Клинически острый синусит/риносинусит (ОС/ОРС) характеризуется внезапным появлением двух или более симптомов, из которых основными являются: 1) затруднение носового дыхания/заложенность носа и 2) выделения из носа/стекание отделяемого из носоглотки в ротоглотку. Также могут быть: 3) боль/давление в области лица в проекции околоносовых пазух, 4) снижение/потеря обоняния $[3,4]$. При ОРС указанные симптомы сохраняются не более 12 нед. и полностью исчезают после выздоровления [5]. При рецидивирующем остром риносинусите периоды между обострениями составляют не менее 8 недель [8]. Длительность клинических проявлений более 12 недель характеризует хронический риносинусит.
Согласно классификации EPOS-2012 различают вирусный, поствирусный и бактериальный острый риносинусит [5]. Продолжительность острого вирусного синусита/риносинусита менее 10 дней, заболевание не прогрессирует. При первичном бактериальном синусите клинические симптомы сохраняются 10 дней и более, или наблюдается прогрессирование симптомов в течение 10 дней [4]. Присоединение вторичной бактериальной инфекции осложняет течение заболевания, затягивает выздоровление, создает условия для персистенции возбудителей и перехода острого воспаления в хроническое. Доля вторичной инфекции при развитии синусита у взрослых составляет 0,5-2\% [7].

Среди этиологических факторов ОРС преобладают вирусные инфекции - 90-98\%, бактериальной инфекции принадлежит от 2 до 10\% [8]. Особой «тропностью» к слизистой оболочке носа и околоносовых пазух обладают риновирусы. Наиболее значимыми бактериальными возбудителями ОРС являются Streptococcus pneumonia 19-47\%, Haemophylus influenzae - 26-47\%, их асcоциации - 7\%. Реже обнаруживаются стрептококки не группы A - 1,5-13\%, S.pyogenes - 5-9\%, негемолитические стрептококки - 5\%, S.aureus - 2\%, M.catarrahalis - $1 \%$, H.parainfluenzae - 1\%, грамотрицательные патогены редко. Отмечается увеличение доли атипичных возбудителей острого риносинусита - хламидий, микоплазм, что обосновывает включение в диагностический алгоритм 
методик ИФА, ПЦР. Представители факультативно-анаэробной микрофлоры - Peptostreptococcus, Fusobacterium, Prevotella, Porphyromonas участвуют в поддержании острого воспаления слизистой оболочки околоносовых пазух и способствуют переходу острого воспалительного процесса в хронический [8].

\section{Согласно классификации EPOS-2012 различают вирусный, поствирусный и бактериальный острый риносинусит}

В настоящее время дифференциация острого бактериального синусита по наличию «гнойного» экссудата беложелтого и даже зеленоватого цвета в очаге воспаления не считается доказательной. Этот клинический симптом выявляется и при вирусном поражении, что объясняют высокой степенью привлечения в подслизистый слой и эпителий полинуклеаров за счет выделения провоспалительных цитокинов поврежденными клетками эпителия. Зеленоватый цвет экссудата связывают с наличием в нем пероксидазы [9] и примеси фибрина [10], свойственных воспалительной реакции. Это обосновывает необходимость комплексной оценки эпидемиологических данных, клинических симптомов, результатов дополнительных лабораторных, микробиологических, инструментальных исследований при назначении лечения ОРС.

Лечение ОРС осуществляется с учетом этиологии, патогенеза заболевания, степени тяжести, наличия осложнений, сопутствующей патологии, возраста пациента, результата проводимого ранее лечения. Этиотропная противовирусная терапия при ОРС малоэффективна, так как эффективна в отношении конкретных вирусов и их серотипов, преимущественно вирусов гриппа. Используются препараты с неспецифическим механизмом противовирусной активности - иммуномодуляторы и гомеопатические препараты с высоким уровнем доказанной эффективности [11]. Антибактериальная терапия при неосложненном течении вирусного воспаления не предотвращает бактериальную суперинфекцию, напротив, подавляет нормальную микрофлору респираторного тракта, сдерживающую активное размножение стафилококков и кишечной флоры $[9,12,13]$. Назначение антибактериальных препаратов при вирусных поражениях ЛОР-органов и недоказанной или неподтвержденной бактериальной природе заболевания считается ошибочным и опасным в связи с возможным развитием побочных эффектов, в том числе повышением резистентности к антибиотикам. В связи с этим при лечении ОРС повышается роль патогенетически обоснованной терапии.

В патогенезе острого синусита/риносинусита важную роль играют нарушения мукоцилиарного транспорта и аэрации околоносовых пазух, изменение интенсивности выработки, состава и реологических свойств носовой слизи, что на фоне воспалительного отека слизистой оболочки полости носа и околоносовых пазух приводит к скоплению воспалительного экссудата. Это способствует более продолжительному течению местного воспалитель- ного процесса, вовлечению смежных областей как по имеющимся анатомическим сообщениям, в частности через слуховую трубу в полости среднего уха, посредством общего респираторного тракта в нижние дыхательные пути, так и посредством общих путей кровообращения, лимфообращения и контактно с развитием глазничных и внутричерепных осложнений. Механизмы патогенеза ОРС обосновывают необходимость и важность проведения противовоспалительной, противоотечной, мукорегулирующей, секретомоторной и секретолитической терапии.

Большое значение в лечении ОРС имеет восстановление нормального функционирования клеток респираторного эпителия, бокаловидных, слизистых желез, качественных и количественных характеристик слизи, мукоцилиарного транспорта, микробиологических составляющих нормобиоценоза. Современные синтезированные лекарственные средства, как правило, решают какуюлибо одну задачу, поэтому схемы лечения нередко содержат несколько препаратов, что создает опасность полипрагмазии [11, 14-17]. Кроме возможного взаимодействия используемых препаратов, отрицательной стороной такого лечения является большая лекарственная нагрузка на ослабленный болезнью организм пациента. Поэтому особое внимание в выборе лекарственных средств при ОРС уделяется использованию фитопрепаратов комплексного действия, что нашло отражение в нормативных документах - группа фитопрепаратов (herbal medicine) в последнем издании EPOS введена в рекомендации по лечению ОРС у взрослых [6]. Согласно этим документам, фитотерапевтические лекарственные средства с секретолитической активностью показаны при вирусных и поствирусных формах риносинуситов с высокой степенью достоверности результатов (Ib) и высочайшим уровнем рекомендаций (A) [6]. Среди фитопрепаратов указано два лекарственных средства: экстракт корней пеларгонии сидовидной (Pelargonium sidoides, Умкалор) и Миртол (Myrtol, ГелоМиртол ${ }^{\circledR}$, ГелоМиртол ${ }^{\circledR}$ форте).

\section{Антибактериальная терапия при неосложненном течении вирусного воспаления не предотвращает бактериальную суперинфекцию, напротив, подавляет нормальную микрофлору респираторного тракта}

Миртол стандартизированный представляет собой оригинальный растительный комплекс, стандартизированный по содержанию трех растительных компонентов: лимонена, цинеола, а-пинена. Эти природные углеводороды являются основными компонентами натуральных масел, преимущественно эвкалиптового и миртового. Стандартизация обеспечивает точность дозирования действующего вещества и прогнозируемый терапевтический эффект. Благодаря стандартизации изучена фармакокинетика действующего вещества Миртол:

- быстрое всасывание в тонком кишечнике (относительная биодоступность составляет 95,6\%), 
достижение максимальной концентрации в крови через 1-3 часа после приема per os,

- обнаружение в высоких концентрациях в плазме, мокроте,

выведение из организма различными путями, включая слизистую оболочку дыхательных путей.

Исследование фармакокинетики Миртола доказало его практически полное попадание в общий кровоток, а затем в необходимой концентрации - в очаг воспаления дыхательных путей, где раскрывается полный комплекс фармакологических эффектов: муколитический, секретолитический, секретомоторный, антиоксидантный, противовоспалительный, антибактериальный [18].

- Мукосекретолитический эффект проявляется в снижении вязкости патологически измененного секрета за счет разрыва дисульфидных связей, увеличении секретолиза и частоты колебаний ресничек мерцательного эпителия, что приводит к улучшению оттока секрета из околоносовых пазух и нормализации мукоцилиарного клиренса [19].

- Противовоспалительное и антиоксидантное действие обусловлено нейтрализацией агрессивных ОН-радикалов кислорода, подавлением синтеза этилена и снижением уровня гистамина [20]. Кроме того, Миртол снижает концентрацию лейкотриенов и простагландина Е2 [6].

- Антибактериальный эффект проявляется в бактериостатическом действии на наиболее частых возбудителей заболеваний дыхательных путей: Streptococcus pneumoniae и Haemophilus influenzae [21].

Благодаря широкому спектру фармакологических эффектов Миртола, его использование в терапии острых неосложненных заболеваний дыхательных путей является патофизиологически обоснованным методом, позволяющим избежать полипрагмазии и существенно снизить частоту назначения антибиотиков [22].

Препараты ГелоМиртол ${ }^{\circledR}$ и ГелоМиртол ${ }^{\circledR}$ форте, содержащие в качестве активного вещества Миртол стандартизированный, применяются в комплексной терапии воспалительных заболеваний дыхательных путей - синуситах и бронхитах острого и хронического течения. Препарат ГелоМиртол ${ }^{\circledR}$ (120 мг) применяется у детей с 6 лет, ГелоМиртол ${ }^{\circledR}$ форте (300 мг) - у взрослых и детей с 10 лет. Применение препаратов у детей до 6 лет не показано в связи с лекарственной формой «капсулы», использование которой не рекомендовано у маленьких детей. Дозировка зависит от течения заболевания и возраста пациента (табл.).

Рекомендуется принимать препарат за полчаса до еды, запивая водой комнатной температуры (в достаточ- ном количестве - примерно 1 стакан). Капсулы препарата растворяются не в желудке, а в кишечнике, благодаря чему активные вещества практически полностью всасываются, попадают в кровоток и в нужной концентрации поступают в дыхательные пути.

\section{Благодаря широкому спектру фармакологических эффектов Миртола, его использование в терапии острых неосложненных заболеваний дыхательных путей является патофизиологически обоснованным методом, позволяющим снизить частоту назначения антибиотиков}

\section{Клиническая эффективность препаратов ГелоМиртол ${ }^{\circledR}$ и ГелоМиртол ${ }^{\circledR}$ форте подтверждена многочисленными исследованиями.}

Накоплен большой клинический опыт применения препаратов на основе Миртола стандартизированного как за рубежом, так и в России. Данные более 100 научных исследований, включивших более 7000 пациентов, в том числе 1000 детей, подтвердили лечебную эффективность и хорошую переносимость препарата.

Применение препарата ГелоМиртол ${ }^{\circledR}$ форте у взрослых. Эффективность Миртола стандартизированного (1 капсула 300 мг 4 раза/сут в течение $6 \pm 2$ дней) в терапии ОРС у взрослых (n = 331) была показана в рандомизированном двойном слепом активно-и плацебоконтролируемом мультицентровом исследовании с уровнем достоверности lb [5, 22]. Анализ результатов лечения показал статистически значимые различия снижения величины общей выраженности симптомов: в основной группе на 10,5 балла, в группе плацебо - на 9,2 балла. Прием Миртола стандартизированного при ОРС позволил воздержаться от проведения антибиотикотерапии у 92,7\% пациентов после $6 \pm 2$ дней лечения, тогда как в группе плацебо у 12,6\% пациентов лечение антибиотиками оказалось неизбежным. На основании полученных данных авторами было сделано заключение о том, что терапия неосложненных ОРС у взрослых Миртолом стандартизированным в комбинации с деконгестантами является рациональной, патогенетически обоснованной.

Применение препарата Геломиртол ${ }^{\circledR}$ у детей. Клинический опыт наблюдения за детьми ( $\mathrm{n}=60)$ в возрасте от 6 до 10 лет показал эффективность и безопас-

\section{Таблица. Режим дозирования препаратов ГелоМиртол ${ }^{\circledR}$ форте и ГелоМиртол ${ }^{\circledR}$ в зависимости от возраста пациента и течения острого риносинусита}

\begin{tabular}{l|c|c|c}
\hline \multirow{2}{*}{} & \multicolumn{2}{|c|}{ ГелоМиртол ${ }^{\circledR}$ форте, капсулы 300 мг №20 } & ГелоМиртол ${ }^{\circledR}$, капсулы 120 мг №20 \\
\cline { 2 - 4 } & Взрослье & Дети старше 10 лет & Дети старше 6 лет \\
\hline Острое воспаление & по 1 капсуле 3-4 раза в день & по 1 капсуле 2 раза в день & по 1 капсуле 3-4 раза в день \\
\hline Хроническое воспаление & по 1 капсуле 2 раза в день & по 1 капсуле 1 раз в день & по 1 капсуле 2-3 раза в день
\end{tabular}


ность Миртола стандартизированного (1 капсула 120 мг 3 раза/сут в течение 7 дней) в лечении неосложненных ОРС [23]. Анализ результатов лечения показал статистически значимое отличие в выраженности заложенности носа уже на 3-й день от начала лечения: 2,4 \pm 0,3 дня в основной группе по сравнению с 3,2 \pm 0,2 дня в группе контроля. Статистически значимые различия в выраженности ринореи и кашля были зафиксированы, соответственно, на 7-й и 14-й день после начала лечения. Продолжительность применения назальных сосудосуживающих капель в качестве симптоматической терапии у пациентов в основной группе составила

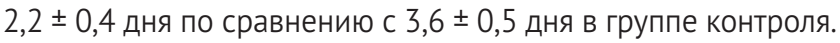

На основании полученных данных было сделано заключение о том, что применение препарата ГелоМиртол ${ }^{\circledR}$ в лечении неосложненных форм ОРС у детей является клинически эффективным, удобным и безопасным методом и может быть рекомендовано к широкому практическому применению.

\section{Миртол - единственное лекарственное средство растительного происхождения, включенное в стандарты Минздрава РФ по лечению острого синусита у взрослых и детей}

\section{Препараты ГелоМиртол ${ }^{\circledR}$ и ГелоМиртол ${ }^{\circledR}$ форте вклю- чены в рекомендации по лечению ОРС.}

Высокий уровень доказательности проведенных исследований обеспечил доверие специалистов к препаратам на основе Миртола стандартизированного и позволил включить их в международные и российские рекомендации по лечению ОРС:

- Миртол включен в Европейские рекомендации EPOS-2012 для лечения вирусного и поствирусного риносинусита с самым высоким классом рекомендаций - A [5]. - Миртол - единственное лекарственное средство растительного происхождения, включенное в стандарты Минздрава РФ по лечению острого синусита у взрослых и детей [24].

- Миртол рекомендован Национальной медицинской ассоциацией оториноларингологов в качестве фитопрепарата для терапии острых синуситов [8, 25].

\section{ВЫводы}

1. Патогенетически обоснованное применение фитосекретолитиков в лечении заболеваний верхних дыхательных путей обеспечивает комплексное действие, позволяющее избежать полипрагмазии и получить лечебный эффект при минимальных дополнительных назначениях.

2. Преобладание вирусной этиологии в генезе воспалительных заболеваний верхних дыхательных путей над бактериальными формами обосновывает более широкие рекомендации к использованию фитосекретолитиков при лечении.

3. Препараты ГелоМиртол ${ }^{\circledR}$ и ГелоМиртол ${ }^{\circledR}$ форте на основе Миртола стандартизированного, обладая ком-

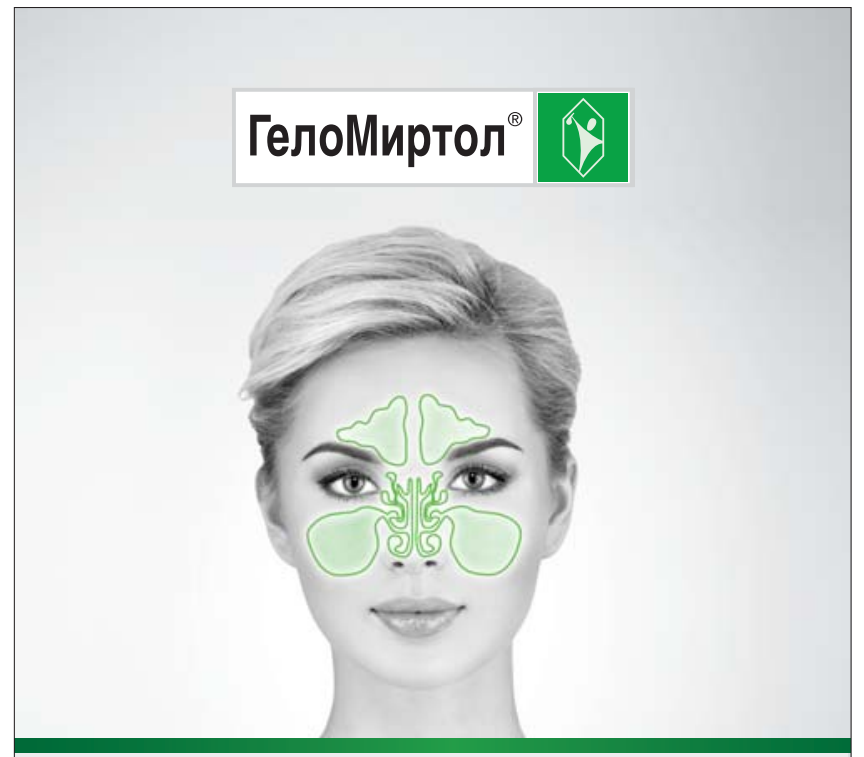

При острых и хронических синуситах

Миртол стандартизированный

$\checkmark$ Секретолитическое, секретомоторное и муколитическое действие ${ }^{[1-3]}$

$\checkmark$ Антиоксидантный эффект в основе противовоспалительного действия ${ }^{[4-5]}$

$\checkmark$ Антибактериальное действие на самые частые возбудители синуситов Str. Pneumoniae, Hämophilus influenzae

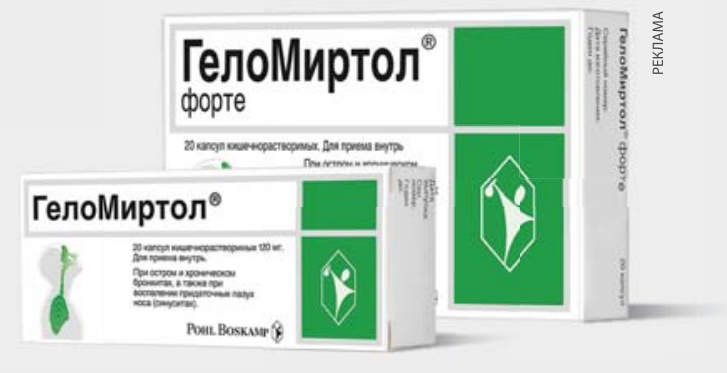

Информация предназначена исключительно для фармацевтических и медицинских работников

Эксклюзивный дистрибьютор: АО «Европлант», 143444, Московская обл Ккрасногорск, мкр. Опалиха, ул. Мира, 25, +7 (495) 705-93-79

Производитель: Г Поль-Боскамп ГмбХ\& Ко КГ 25551 Хохенлокштедт, Килер штрассе, 11, Германия. Регистрационные удостоверения: П № 013662/01 от 03.04.2013, П № 012303/01 от 12.12.2008.

'Beuscher N, Bien E, Elister EF Kietzmann M and Amon UE, Myrtol standardized in treatment of sinusitis and bronchits - Pharmacodynamics and pharmacokinetics, Zeitschrift für Phytotherapie, Abstractband, Kongress der Gesellschaft für Phytotherapie 1997, Seiten 9-10. ${ }^{2}$ Lenders H et al., Suitability of various methods as pharmacodynamic models for the investigation of the efficacy of mucolytic agents on the maxillary sinus, Naunyn-Schmiederberg's Arch. Pharmacol. (1996) 353 (Suppl.) R151. ${ }^{3}$ App EM, Stellenwert der Mukusclearance für das Bronchialsystem Pathophysiologie und therapeutische Ansätze, in: Meister R, Entzündliche Erkrankungen des Pathophysiogie und therapeutische Ansatze, in: Meister R, Entzundiche Erkrankungen des Bronchialsystems, Springer Verlag, 1. Auflage 2000, Seiten 27-53. "Grabmann J, Hippeli S, Dornisch K, Roh,

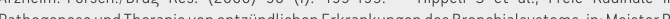
Entzündliche Erkrankungen des Bronchialsystems, Springer Verlag 1. Auflage 2000, Seiten 1-25. 
плексным действием - мукоактивным, противовоспалительным, антибактериальным, являются патогенетически обоснованными, позволяют избежать назначения антибиотиков при легких формах ОРС и уменьшить лекарственную нагрузку при необходимости назначения системных антибиотиков.

4. Клинический опыт применения препаратов ГелоМиртол ${ }^{\circledR}$ у детей и ГелоМиртол ${ }^{\circledR}$ форте у взрослых показал хорошую переносимость и высокий профиль безопасности при достоверном снижении выраженности симптоматики и потребности в симптоматической терапии острых неосложненных риносинуситов.

5. Действующее вещество препаратов ГелоМиртол ${ }^{\circledR}$ и ГелоМиртол ${ }^{\circledR}$ форте Миртол стандартизированный включен в Европейские рекомендации EPOS-2012 по лечению вирусного и поствирусного риносинусита с самым высоким классом рекомендаций - А, стандарты Минздрава России по оказанию первичной медикосанитарной помощи при остром синусите, методические рекомендации «Принципы этиопатогенетической терапии острых синуситов - 2015», одобренные Национальной медицинской ассоциацией оториноларингологов, рекомендации Национальной медицинской ассоциации оториноларингологов по лечению ОС у взрослых и детей с 6 лет.

Конфликт интересов: авторы заявляют об отсутствии конфликта интересов в ходе написания данной статьи.

\section{ЛИТЕРАТУРА}

1. Пискунов Г.З., Пискунов С.З. Клиническая ринология. М.: Миклош, 2002. 390 с./ Piskunov GZ, Piskunov SZ. Clinical rhinology. M.: Miklos, 2002. 390 p.

2. Карпова Е.П. Риносинусит или «банальная простуда» у детей. Лечащий врач, 2016, 12 (специальный оттиск): 1-7. wwwlvrach.ru./ Karpova, EP. Rhinosinusitis or a "banal cold" in children. Lechashchiy Vrach, 2016, 12 (special impression): 1-7. wwwlvrach.ru.

3. Maniglia AJ, Goodwin WJ, Arnild JE et al. Intracranial abscesses secondary to nasal, sinus, and orbital infections in adults and children. Arch. Otolaryngol Head Neck Surg, 1989 115: 1424-1429.

4. Рязанцев С.В., Коноплев О.И., Кривопалов А.А., Шаталов В.А. Мукоактивная терапия острых синуситов с использованием препарата на основе карбоцистеина лизиновой соли. Медицинский совет, 2015, 11: 27-30./ Ryazantsev SV, Konoplev OI, Krivopalov AA, Shatalov VA. Mukoactive therapy for acute sinusitis using a carbocysteine lysine salt-containing drug. Meditsinsky Sovet, 2015, 11: 27-30.

5. Fokkens WJ, Lund VJ, Mullol J, Bachert C, Alobid I, Baroody F, et al. European Position Paper on Rhinosinusitis and Nasal Polyps. Rhinol Suppl, 2012 Mar, 23: 40-41.

6. Beuscher N, Keitzmann M, Bien E, Champeroux P. Interference of Myrtol standardized with inflammatory and allergic mediators. Arzneimittelforschung, 1998, 48: 985-989.

7. Sanchez GV, Hicks LA. Acute sinusitis and pharyngitis as inappropriate indications for antibiotic use. Antimicrob Agents Chemother, 2014, 58: 3572

8. Острый синусит: методические рекомендации. Под ред. С.В. Рязанцева. СПб.: Полифорум Групп, 2017. 32 с. /Acute sinusitis: methodological recommendations. Edited by Ryazantsev SV. SPb.: Poliforum Group, 2017. 32 p.

9. Федеральные клинические рекомендации по оказанию медицинской помощи детям с острой респираторной вирусной инфекцией (острый назофарингит). МЗ РФ, Союз педиатров России, 2015.12 c. /Federal clinical guidelines for the provision of medical care to children with acute respiratory viral infection (acute nasopharyngitis). Ministry of Health of the Russian Federation, Union of Pediatricians of Russia, 2015.12 p.

10. Острые респираторные вирусные инфекции у взрослых: Клинические рекомендации. Утв.
Решением Пленума правления Нац. науч. общества инфекционистов 30 окт. 2014 г. 2014. 69 c. /Acute respiratory viral infections in adults: Clinical guidelines. Approved by the Order of the Plenum of the Board of Nat. Sci. Society of Infectious Diseases of Oct. 30, 2014, 2014. 69 p.

11. Карнеева О.В.. Рязанцев С.В.. Радциг Е.Ю., Ким И.А. Возможности клинической гомеопатии в комплексной терапии острых воспалительных заболеваний верхних дыхательных путей: Метод. рекомендации. М.; СПб., 2017. 40 с. / Karneeva OV, Ryazantsev SV, Radtsig EYu, Kim IA Therapeutic potential of clinical homeopathy in the combination therapy of acute inflammatory diseases of the upper respiratory tract: Method. recommendations. M.; SPb., 2017. 40 p.

12. Тец В.В., Накатис Я.А. Инфекции глотки, носа, уха. Гл. 3. Микроорганизмы и антибиотики. Инфекции в оториноларингологии. СПб.: КЛЕT, 2009: 49-115. /Tets W, Nakatis YaA. Infections of pharynx, nose, ear. Ch. 3 . Microorganisms and antibiotics. Infections in otorhinolaryngology. St. Petersburg: KLE-T, 2009: 49-115.

13. Kenealy T, Arroll B. Antibiotics for the common cold and acute purelent rhinitis. Cochrane Database Syst Rev, 2013, 6: CD000247.

14. Савенкова М.С. Многоликая острая респираторная инфекция: от основных возбудителей к выбору препаратов. Лечащий врач, 2011, 3 : 58-64./ Savenkova MS. The many faces of acute respiratory infection: from the main pathogens to the choice of drugs. Lechashchiy Vrach, 2011, 3: 58-64.

15. Зайцева С.В., Зайцева О.В. Острые респираторные инфекции у детей: этиопатогенетические возможности современной терапии.

Медицинский совет, 2014, 5: 22-30./Zaitseva SV, Zaitseva OV. Acute respiratory infections in children: the etiopathogenetic potential of mod ern therapy. Meditsinsky Sovet, 2014, 5: 22-30.

16. Дворецкий Л.И. Лечение больных острыми респираторными заболеваниями: есть ли альтернатива полипрагмазии? Consilium Medicum 2008, 10(10): 10-14. /Dvoretsky LI. Treatment of patients with acute respiratory diseases: is there an alternative to polypragmasy? Consylium Medicum, 2008, 10 (10): 10-14

17. Ключников С.О. Полипрагмазия: пути решения проблемы. Детские инфекции, 2014, 4: 36-39. Klyuchnikov SO. Polypragmasy: ways to solve the problem. Detskie Infektsii, 2014, 4: 36-39.
18. Виттиг Т. Миртол стандартизированный. Клиническая документация, Россия, 2009, 1-е изд., ISBN 3-8796-071-6: 22-45. Wittig T. Myrtol standardized. Clinical documentation, Russia, 2009, 1 st ed., ISBN 3-8796-071-6: 22-45.

19. Lai Y, Dilidaer D, Chen B, Xu G, Shi J, Lee RJ, Cohen NA. In vitro studies of a distillate of rectified essential oils on sinonasal components of mucociliary clearance. American journal of rhinology and allergy, 2014, 28(3): 244-248.

20. Grassmann J, Hipelli S, Dornisch K, Rohnert U, Beuscher N, Elstner EF. Antioxidant Properties Of Essential Oils. Possible explanations for their anti-inflammatory effects. Arzneimittelforschung, 2000, 50(02): 135-139.

21. Christoph F, Kaulfers P, Stahl-Biskup E. In vitro Evaluation of the Antibacterial Activity of $\beta$-Triketones Admixed to Melaleuca Oils. Planta Med, 2001, 67(08): 768-771.

22. Federspil P, Wulkow R, Zimmermann T. Effects of standardized Myrtol in therapy of acute sinusitis-results of a double - blind, randomized multicenter study compared with placebo. Laryngorhinootologie, 1997 Jan, 76(1): 23-7.

23. Карпова Е.П., Емельянова М.П., Тулупов Д.А. Стандартизированные фитопрепараты в терапии острых риносинуситов у детей. Педиатрия им. Г.Н. Сперанского, 2016, 95(1): 97-105./ Karpova EP, Emelyanova MP, Tulupov DA. Standardized herbal medicines in the treatment of acute rhinosinusitis in children. Pediatriya Im. G.N. Speranskogo, 2016, 95 (1): 97-105.

24. Приказ Министерства здравоохранения Российской Федерации от 20 декабря 2012 г. № 1201 н «Об утверждении стандарта первичной медико-санитарной помощи при остром синусите». /Order of the Ministry of Health of the Russian Federation No. 1201 of December 20, 2012 Approval of the Standard for Primary Health Care for Acute Sinusitis.

25. Абдулкеримов Х.Т., Гаращенко Т.И., Кошель В.И., Рязанцев С.В., Свистушкин В.М. Принципы этиопатогенетической терапии острых синуситов: методические рекомендации. СПб.: Полифорум Групп, 2015: 35-36./ Abdulkerimov KhT, Garashchenko TI, Koshel VI, Ryazantsev SV, Svistushkin VM. Principles of the etiopathogenetic therapy of acute sinusitis: methodological recommendations. SPb. Poliforum Group, 2015: 35-36. 